\title{
Assessment on the movement of the steel cylinder during the remove process
}

\author{
Wenbin Liu ${ }^{1,2,3,4^{*}}$ \\ ${ }^{1}$ Tianjin Port Engineering Institute Co., Ltd. Of CCCC First harbor engineering Co., Ltd., Tianjin, 300222, China \\ ${ }^{2} \mathrm{CCCC}$ First Harbor Engineering Company Ltd., Tianjin, China \\ ${ }^{3}$ Key Laboratory of Port Geotechnical Engineering, Ministry of Communications, PRC, Tianjin, China \\ ${ }^{4}$ Key Laboratory of Port Geotechnical Engineering of Tianjin, Tianjin, China
}

\begin{abstract}
The plugged-in steel cylinder plays a key role in building a fast quay wall of the man-made island. The installed steel cylinder will be partly removed to establish a better construction environment in practical cases. This paper analyzed the movement of plugged-in cylinder during remove stage with numerical simulation method. The data from a practical case was calculate to exhibit the analysis procedure.
\end{abstract}

\section{Brief introduction of the research history}

The plugged-in steel cylinder structure is a new type structure for building the island wall, and gains popularity in many recent projects, such as the Hong Kong-Zhuhai-Macao (HKZM) Bridge and ShenzhenZhongshan Channel. It is because that the plugged-in steel cylinder could be installed quickly and conveniently with a low cost, and its short-term stability is also relatively high. The movement of plugged-in cylinder during and after the construction period is a hot study scope now with its wide application in engineering cases.

Sun and Wang [1,2] take a good use of the advantage of the simplified analytical model and finite element model in studying plugged-in cylinder, and proposed an analysis model to analyse the deformation of the plugged-in cylinder based on the effective dynamic stress. Meng $[3,4]$ proposed a new contact surface element to improve the seabed soil-shell interaction model for the large diameter cylinder in the simulation. Chen $[5,6]$ analysed the distribution of positive and passive soil pressure, the inside soil-cylinder friction resistance and the outside soil-cylinder friction resistance by applying the 3D rigid-plastic contact surface element. Wang [7] solved the deformation of the shell of the plugged-in cylinder from the view of the plane strain method and analysed the movement of the independent plugged-in cylinder with the help of the MARC software. Fan $[8,9]$ analysed the movement of plugged-in cylinder under the consideration of the cyclic loading.

However, the movement of the plugged-in cylinder during remove process draws little attentions, and it is also important for engineering practice. This paper focus on this phenomenon and try to make some contributions in this scope. The following work was conducted with PLAXIS 3D to show how cutting and remove process affects on the movement of the plugged-in cylinder.

\section{Details of the practical case}

The practical case is a man-made island construction project. The plugged-in cylinders are installed and connected to form the bulkhead wall of the island. The thickness and outer diameter of the corss section of the plugged-in cylinder are $0.019 \mathrm{~m}$ and $28 \mathrm{~m}$. The length and thickness of connector between two plugged-in cylinders are $110.55 \mathrm{~m}$ and $0.004 \mathrm{~m}$. The elevation of the top of the plugged-in cylinder is $+3.1 \mathrm{~m}$ after the plugged-in cylinder is installed. During the construction period of the man-made island, the plugged-in cylinder will be cut piece by piece for establish a better construction environment, and the elevation of the top of the plugged-in cylinder will fall to $-3 \mathrm{~m}$.

The specific geotechnical parameters of the seabed layers in this case are listed in Table 1. The elevation of the mudline of the seabed is $-14.74 \mathrm{~m}$.

Table 1 Information of the seabed soil

\begin{tabular}{|c|c|c|c|c|c|c|c|}
\hline \multirow[b]{2}{*}{ Layer } & \multirow[b]{2}{*}{ Soil } & \multirow{2}{*}{$\begin{array}{l}\text { Elevation of } \\
\text { the bottom } \\
\text { of layer }(\mathrm{m})\end{array}$} & \multirow{2}{*}{$\begin{array}{l}\text { Weight } \\
\mathrm{kN} / \mathrm{m}^{3}\end{array}$} & \multirow{2}{*}{$\begin{array}{c}\text { Sub-merged } \\
\text { weight } \\
\left(\mathrm{kN} / \mathrm{m}^{3}\right) \\
\end{array}$} & \multirow{2}{*}{$\begin{array}{c}\text { compressing } \\
\text { modulus } \\
(\mathrm{MPa})\end{array}$} & \multicolumn{2}{|c|}{ Shearing strength } \\
\hline & & & & & & $\begin{array}{c}\text { Cohesion } \\
(\mathrm{kPa})\end{array}$ & $\begin{array}{c}\text { Inner friction } \\
\text { angle }\left({ }^{\circ}\right)\end{array}$ \\
\hline (2) 1 & Mud & -23.74 & 15.4 & 5.4 & 1.8 & 4.1 & 4.4 \\
\hline (2) 21 & $\begin{array}{l}\text { Sility } \\
\text { clay }\end{array}$ & -26.24 & 17.6 & 7.6 & 2.8 & 9.3 . & 15 \\
\hline
\end{tabular}




\begin{tabular}{|c|c|c|c|c|c|c|c|}
\hline (2) 2 & Clay & -27.94 & 16.3 & 6.3 & 1.93 & 6.7 & 11.8 \\
\hline (2) 21 & $\begin{array}{c}\text { Sility } \\
\text { clay }\end{array}$ & -33.14 & 17.6 & 7.6 & 2.8 & 9.3 & 15 \\
\hline (3) 6 & $\begin{array}{c}\text { Coarse } \\
\text { sand }\end{array}$ & -34.34 & 19.4 & 9.4 & 12.42 & 12.6 & 32 \\
\hline (6) 12 & $\begin{array}{l}\text { Strong- } \\
\text { weather } \\
\text { ed rock }\end{array}$ & -42.54 & 19.2 & 9.2 & 5.9 & 12.6 & 5 \\
\hline (6) 13 & $\begin{array}{c}\text { Weathe } \\
\text { red } \\
\text { rock }\end{array}$ & -50 & 20.6 & 10.6 & 20 & 3000 & 0 \\
\hline
\end{tabular}

Based on the field testing results, the regular height and period of the wave in the construction yard are $2 \mathrm{~m}$ and $1.6 \mathrm{~s}$, respectively. The mean value of the water depth is $7.8 \mathrm{~m}$. Therefore, the maximum value of the wave force and moment, which acts on the nearshore side of the plugged cylinder, are $638 \mathrm{kN}$ and $2932 \mathrm{kN} \cdot \mathrm{m}$ according to the calculation formulas in the code 'Hydrological code for port and waterway' (JTS 1452015).

\section{Simulation of the displacement of the plugged-in cylinder}

The plugged-in cylinder was simulated with PLAXIS 3D. For reducing the boundary effect, the seabed model used in simulation was $220 \mathrm{~m}$ long, $12 \mathrm{~m}$ deep. In practice, the plugged-in cylinders are welded with each other to form a wall. Therefore, the width of the seabed equals to the outer diameter of the plugged-in cylinder to simulate this limit support from seabed. The load application numerical simulation procedure is: (1) First, establishing the in-site geo-stress of the origin soil layer; (2) Activating the plugged-in cylinder and the backfilled sand inside of the plugged-in cylinder to simulate the installation process; (3) Third, removing part shell of the plugged-in cylinder and the sand inside of the plugged-in cylinder wall to simulate the remove process; (4) Acting the lateral wave force to calculate the displacement of the plugged-in cylinder and check the movement. Fig.1 shows the distribution of the lateral displacement and the changing safety coefficient of movement. And the final safety coefficient after the remove is 2.81 .

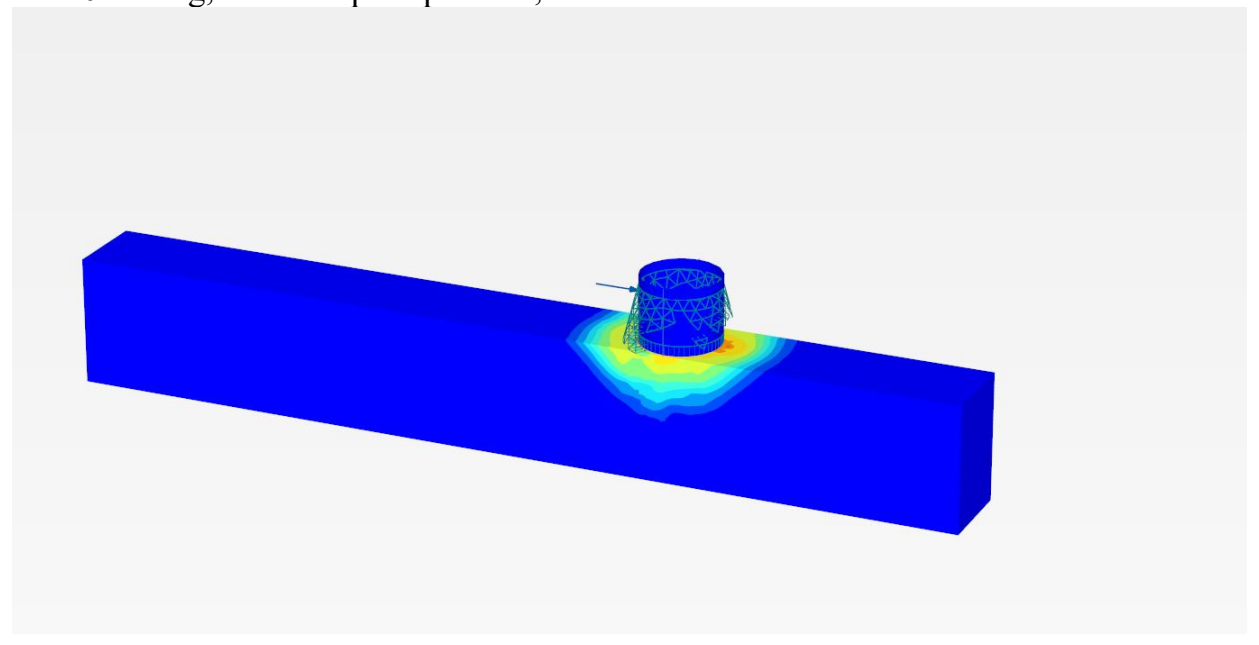

Figure 1 Distribution of cylinder movement

\section{Conclusions}

Our paper studied the movement of plugged-in cylinder during the remove stage through the commercial software PLAXIS 3D. The safety coefficient of the plugged-in cylinder after the finish of remove stage is 2.81 .

\section{References}

1. Sun KL. The interaction between plugged-in cylinder and soil [D]. Tianjin, 1999.

2. Wang YZ, Zhu ZY, Zhou ZR. Dynamic response analysis for embedded large-cylinder breakwaters under wave excitation[J]. China Ocean Engineering, 2004, 18 (4): 585-594.

3. Zhu ZY, Dynamic response of large diameter cylinder breakwater structure under the wave impact [D]. Tianjin, 2003.

4. Meng QW, Wang YZ. Coupled analysis of contactface element and elastic nonlinear element for interaction of large-diameter shell and soil body[J]. China Harbour Engineering, 1999, 2.

5. Chen FQ, Gong XN. Analysis of large cylinder wharf structures using finite element method[J]. Hydro-Science and Engineering, 2001, 4: 37-40.

6. Chen FQ, Yang M. Numerical analysis of behavior of large diameter cylindrical wharf structure[J]. Journal of Tongji University, 2002, 30(7): 797-801. 
7. Wang G, Chen Y, Zhang JM. Finite element method for analyzing overturn stability of large cylindrical structures[J]. Rock and Soil Mechanics, 2006, 27(2): 238-241.

8. Fan QL. A study on stability of deeply-embedded large-diameter cylindrical structure in soft ground[D]. Dalian, 2007.

9. Fan QL, Luan MT, Yang Q et al. Analyses of bearing capacity for deeply-buried large-diameter ylindrical structure on soft clay considering cycliesoftening effect $[\mathrm{J}]$. Journal of Dalian University of Technology, 2006, 46(5): 702-706. 